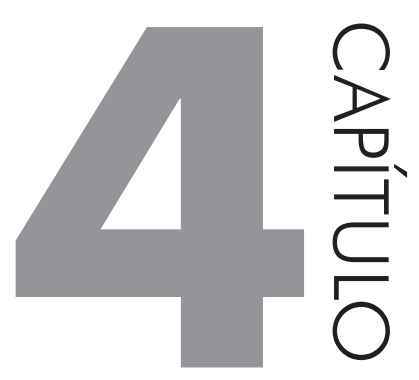

\title{
TEMPO SOCIAL E TEMPO COGNITIVO NA FORMAÇÃO DE PROFESSORES DE INGLÊS PARA A ENVELHESCÊNCIA E TERCEIRA IDADE
}

É preciso formular políticas públicas que proporcionem uma formação especializada de professores para atender a envelhescentes e pessoas de terceira idade, tendo em vista suas necessidades pedagógicas específicas. É preciso também contribuir para o desenvolvimento de metodologias específicas de ensino, de modo que esse público seja tratado de forma humanística, conforme princípios da gerontagogia (PEREIRA, 2009).

Por isso, reiteramos que ensinar inglês para envelhescentes e pessoas da terceira idade é diferente de ensinar para crianças e adolescentes, tradicional público-alvo dos cursos de formação de professores. Como já dissemos, com o crescimento da população envelhescente e da terceira idade, é preciso preparar as pessoas que vão lidar com esse público. Vamos, agora, sumarizar os resultados de nossa pesquisa e sistematizar quais são as contribuições para a formação de professores.

Retomando os resultados do tempo de leitura silenciosa e em voz alta, constatamos que, embora existam diferenças entre os grupos de participantes, esse tempo, em milissegundos, não é suficiente para justificar a hipótese inicial de que envelhescentes e pessoas da terceira idade precisam de mais tempo para o desempenho das tarefas a serem executadas em leitura. Como dissemos, esse resultado 
em milissegundos pode ser relevante no caso de uma concessão de carteira de habilitação (um milissegundo de diferença pode causar um acidente, por exemplo), mas não para uma aula de inglês. A medida evidencia que a demanda de tempo de leitura não interfere na duração de tempo das aulas do curso de extensão, o que comprovamos também.

Esse resultado ajuda a desfazer o mito de que pessoas mais velhas são mais lentas e que por isso teriam mais dificuldades, necessitando de mais tempo para as atividades. Esse resultado contraria a hipótese (e convicção da própria pesquisadora!), que, como a maioria das pessoas, tinha a crença de que ao idoso deveria ser dado mais tempo para a execução de tarefas. Essa ideia pré-concebida e preconceituosa foi desfeita diante da evidência dos resultados. A mudança de concepção da pesquisadora é, também, um resultado.

A investigação do número e da duração das fixações durante o movimento de leitura apontou que envelhescentes e pessoas de terceira idade realizam mais fixações com uma duração média maior. Os jovens fazem menos fixações do que os envelhescentes e pessoas da terceira idade, o que é natural da idade, devido à fisiologia humana e perdas da plasticidade muscular, o que explica essa diferença do tempo de leitura. Esse resultado corrobora a hipótese da perda de acurácia, devido à idade, pois, como vimos, fisiologicamente, músculos mais enrijecidos necessitam de um maior tempo. Novamente, destacamos que esse resultado pode contribuir para o desenvolvimento de materiais didáticos apropriados para o público. Em termos de formação de professores para atuarem com esse público, podemos destacar a necessidade de se considerar esse fator na hora de desenvolver materiais didáticos de suporte à leitura, com uma diagramação que permita movimentos confortáveis de sacadas (mancha da página mais estreita, por exemplo). Novas pesquisas precisam ser empreendidas nesse campo.

A crença de que o idoso necessita de mais tempo para a execução das tarefas, no que tange ao ensino de uma língua estrangeira, precisa ser desmistificada. Nas aulas do curso de extensão, constatamos que o tempo fora superdimensionado, pois, nas análises das tarefas dos planejamentos das aulas e aulas executadas, a hipótese inicial também foi desfeita. No entanto, observa-se que houve uma convergência entre esse estudo e o estudo de leitura: o tempo foi superior nas tarefas de teste emocional e coffee break e também nas revisões de gramática e novos vocabulários das novas lições. As primeiras atividades se referem ao tempo social, enquanto a última está voltada para questões pedagógicas, o que, de certa forma, seria esperado demandar menos tempo.

Quanto ao estado emocional, as análises dos testes de entrada e testes de saída das aulas mostram que os participantes chegam com motivações positivas e 
saem de maneira positivas também, e, quando chegam com motivações negativas, mudam para positivas. Esse cenário é diferente, por exemplo, de cursos regulares, com frequência obrigatória. No tipo de curso aqui analisado, os participantes vão espontaneamente. Assim, o professor que atua com esse público precisa ser preparado para manter a motivação desses participantes a fim de que não abandonem o curso, o que é diferente de motivar um participante que chega desmotivado.

Diversos autores discutem sobre a terceira idade e suas necessidades pedagógicas específicas. Pereira (2014) faz um levantamento histórico das últimas décadas do final do século XX sobre longevidade, destacando trabalhos científicos na área da "gerontologia básica" e um texto crítico sobre a universidade aberta. Lima (2001) evidencia a existência de um campo de estudos voltados a gerontologia educacional, que trata de uma pedagogia específica de ensino para os sujeitos de terceira idade. Stano (2001) relata questões voltadas ao envelhecimento e suas relações com o processo de ensino-aprendizagem no espaço escolar.

Knowles, Holton e Swanson (2005) apresentam cinco princípios de aprendizagem em adultos, ressaltando a importância da andragogia. O primeiro princípio se refere aos seus próprios interesses, necessidades de aprendizagem ou de continuidade de praticar a mesma ação. O segundo princípio diz respeito a uma aprendizagem autônoma ou por uma orientação de instrução de um especialista. O terceiro princípio visa à priorização das ferramentas ou recursos de aprendizagem e também como o seu ritmo de aprendizagem se processa. O quarto princípio de aprendizagem diz respeito à prontidão que esse público tem em relação às ações da vida e como suas tarefas são cumpridas. O quinto princípio é o problema central e contextual sobre uma orientação de aprendizagem para esse público.

Os princípios de aprendizagem da andragogia seguem as motivações necessárias de valor intrínseco, isto é, de dentro para fora, e sem espera de retorno financeiro. Os aprendizes desejam aprender com o prazer de se sociabilizarem com o outro e também de se sentirem úteis e participativos na vida, como sempre foram em outras faixas etárias passadas. Assim, terão qualidade de vida e o prazer de viver uma vida longeva.

Como em 2025 o Brasil passará a ser um país de idosos, novas demandas sociais surgirão, a exemplo da preocupação com a qualidade de vida dessa parcela da população. Pessoas já na terceira idade relatam que precisam dar um novo sentido para continuar vivendo de maneira independente e digna. Estão abertas a novos aprendizados e para isso estão dispostas a praticar o exercício da mente para o retardamento do envelhecimento da mente e do corpo. $\mathrm{O}$ acesso à educação, também por meio de cursos de língua estrangeira como o que ofertamos a esse público, contribui com a melhoria de sua qualidade de vida, já que podem 
aumentar sua autoestima, passam a ver o envelhecimento de forma mais natural e positiva, propicia sua integração social e dignidade humana, minimizando, por exemplo, riscos de doenças como depressão e demências do envelhecimento, o que pode ser explorado para a promoção de bem-estar social.

No atual mundo globalizado, é indispensável que tanto os graduandos como a comunidade interajam, com oportunidades de se engajarem em novos projetos voltados à continuidade da escolaridade, ou início de aprendizagem de uma segunda língua, como o inglês.

Viver feliz, sentindo-se inserido e bem recebido em todos os contextos educacionais familiares e sociais para se atingir uma terceira idade plena, com bem estar e qualidade de vida, de modo a fazer com que se sintam realizados, atuantes e mais integrados em seu meio social deve ser objetivo de todos. Se a sociedade conseguir proporcionar isso aos seus envelhescentes, haverá menos desgastes fisiológicos e cognitivos, menos problemas de saúde. O curso de inglês para a terceira idade contribui para essa realização.

Pensemos no impacto social que já estamos vivendo. No ano 2025, professores, alunos, envelhescentes e pessoas da terceira idade terão o desejo de estar envolvidos com um aprendizado de uma língua estrangeira. Esperamos que esta proposta de estudo continue percorrendo a mente dos pesquisadores atuais e do futuro, mostrando que a pesquisa é contínua e inacabada.

O envelhecimento é inerente ao homem, portanto devemos aprender a respeitar os mais velhos e a envelhecer bem. Com essas palavras, não estou me despedindo, mas ratificando a relevância da pesquisa desenvolvida e do curso de extensão, sinalizando a continuidade dos estudos. Ainda há muito a ser feito. 